\title{
A trilogy of tragedies - paediatric dental tooth whitening
}

\author{
Emma Grace Walshaw, ${ }^{* 1}$ Pathanjali Kandiah² and Helen Rodd ${ }^{3}$
}

\section{Key points}

Dental practitioners' indemnity does not currently cover that of dental whitening in paediatric patients.
The treatment options for paediatric patients with non-vital discoloured teeth following dental trauma are limited due to the removal of dental whitening as a treatment option.
The quality of life and psychosocial aspects of a child's life can be negatively affected due to the appearance of untreated discoloured anterior incisors.

\begin{abstract}
Dental tooth whitening is used throughout the United Kingdom for patients who have aesthetic concerns regarding the colour of their teeth. Up until recent months it was also frequently used for paediatric patients with enamel opacities of cosmetic concern and discoloured non-vital anterior teeth. This safe and effective treatment option is now not available to paediatric dental patients due to changes in indemnity cover, and we demonstrate three cases from our department where dental whitening was the most appropriate treatment option. By removing this treatment option for selected paediatric patients, we are concerned that more destructive and less effective treatments may be performed with short- and long-term detriment to their oral health. Furthermore, failure to provide any treatment may negatively affect children's quality of life and psychological well-being.
\end{abstract}

\section{Introduction}

In 2011 the European Union produced a Cosmetic Directive (2011/84/EU) that discussed dental whitening, and explained that products with concentrations above $0.1 \%$ hydrogen peroxide could not be used on anyone under the age of 18 years old. ${ }^{1}$ It was following this directive that the General Dental Council released a statement stating that dental whitening could be undertaken on children under the age of 18 if it was wholly for the purpose of treating or preventing disease. $^{2}$

Tooth whitening has been a point of contention within paediatric dentistry for a number of years. ${ }^{3,4}$ However, there is clear evidence of the hugely positive impact that it can have on young patients' quality of life and self-confidence when treating conditions such as anterior enamel opacities. ${ }^{5}$ It is also well recognised that traumatic dental injuries involving anterior teeth can negatively impact on children's quality of life, and interventions,

'Dental Core Trainee, Sheffield Teaching Hospitals NHS Trust; ${ }^{2}$ Consultant in Paediatric Dentistry, Sheffield Teaching Hospitals NHS Trust; ${ }^{3}$ Professor of Paediatric Dentistry, University of Sheffield

${ }^{*}$ Correspondence to: Emma Grace Walshaw

Email: Emma.walshaw@nhs.net

Accepted 26 September 2019

https://doi.org/10.1038/s41415-019-0950-y including aesthetic treatments, can improve a child's quality of life. ${ }^{6}$

In recent months the use of dental whitening by paediatric dentists within the United Kingdom has been halted, due to indemnity cover concerns, both personal and trust-wide. To the best of our knowledge there are now no paediatric dental departments providing tooth whitening to children under the age of 16 years old in the North of England.

\section{Discussion of cases}

The authors of this article would like to demonstrate three cases where tooth whitening has been the only reasonable option of treatment for patients who have sustained traumatic dental injuries. By removing this option for patients we risk damaging a young child's personal confidence and failing to help improve social interactions in what can be an already difficult period of their life.

Figure 1 demonstrates the case of an 11-year-old boy who avulsed his upper right central incisor while playing at school 18 months before these images being taken. Despite excellent emergency dental care by his local general dentist, with appropriate re-implantation and splinting, this tooth became non-vital and required root canal treatment. The tooth gradually became grey in colour and this significantly affected the young boy's confidence at school, with mum reporting that he 'refused to smile' anymore.

Figure 2 shows the case of a 14-year-old male who presented with a history of falling two years previously while playing with friends. He was referred to our department with self-confidence concerns regarding the appearance of his front tooth and paranoia that people were staring at it constantly. The tooth was root canal filled by his general dental practitioner before referral.

Figure 3 highlights the case of a 13-yearold male who suffered dental trauma when playing ice-hockey with friends three months ago. This patient's upper left central incisor became non-vital secondary to an extensive enamel-dentine fracture shortly after the injury. This patient also complained of feeling self-conscious, and actively covered his mouth when speaking or smiling during his dental consultation on our department.

The patients shown in Figure 1 and Figure 2 both received dental whitening from our department between 2018 and early 2019, before the change in indemnity circumstances. They were pleased with their results, suffered no side effects and requested no further treatment; they have now been discharged for regular review by their general dental practitioner.

Unfortunately, the same cannot be said for the young male from Figure 3. Despite being referred with the same diagnosis and treatment need, we have been unable to offer this treatment 

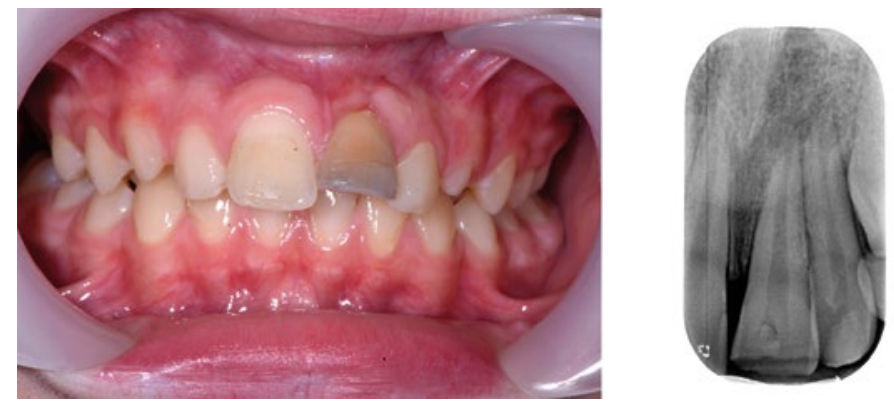

Fig. 1 Demonstrates the case of an 11-year-old boy who experienced trauma to his upper left central incisor. This child had concerns regarding the aesthetics of his teeth, to the point where it was hugely affecting his social interactions
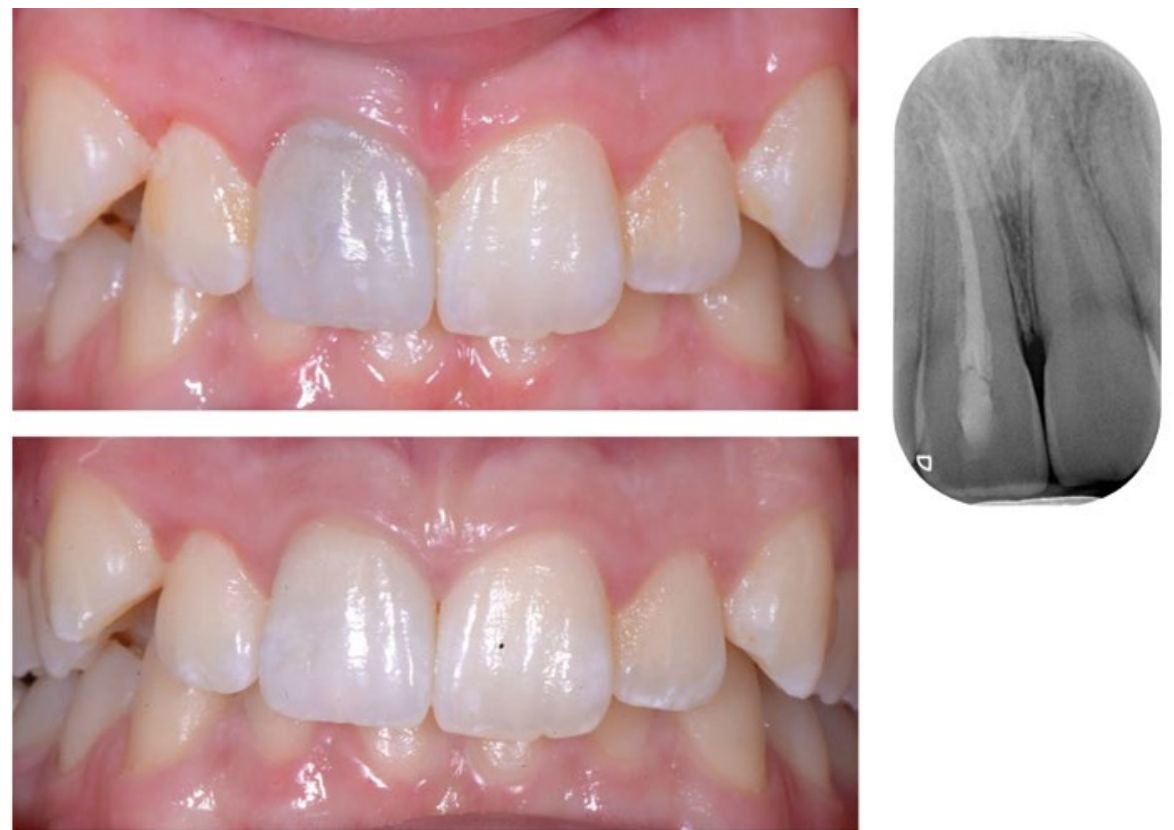

Fig. 2 Shows the case of a 14-year-old male who presented following trauma to his upper right central incisor. The tooth was re-root canal treated in our department, and internal tooth whitening provided. There is demonstrable change in the grey discolouration of his tooth in the post-operative images
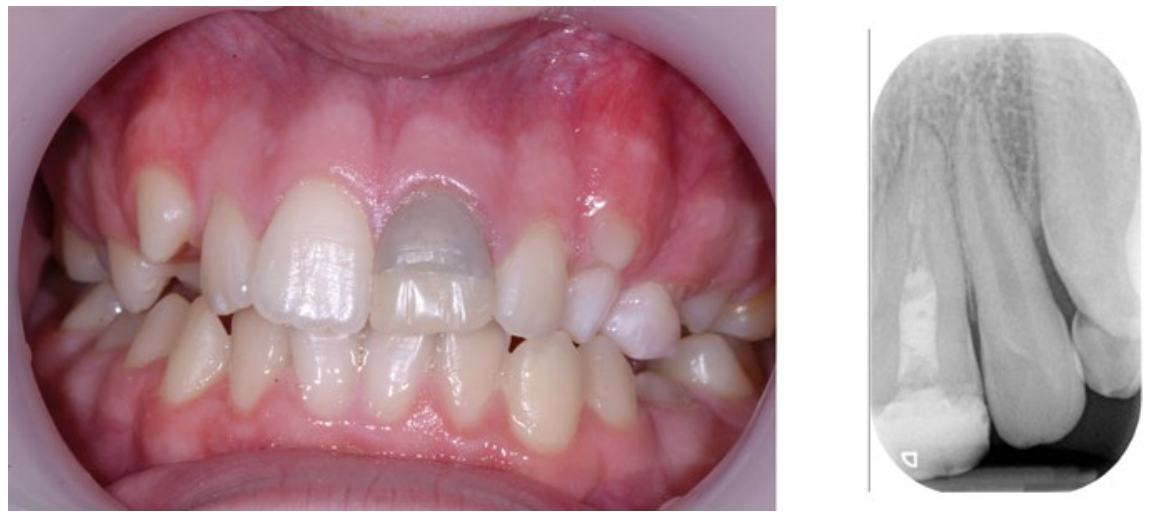

Fig. 3 Highlights the case of a 13-year-old male who suffered dental trauma to his upper left central incisor. This tooth has marked discolouration and is severely affecting the patient's quality of life to him. We have planned for this patient to receive a composite labial veneer following root canal treatment, which will also replace his current incisal restoration. We are sure that all practitioners would agree that the depth of this restoration will need to be significant to mask the underlying discolouration.

The authors are under no illusion that dental whitening is a perfect treatment option; it has well-reported risks which can at worst render a tooth unrestorable. ${ }^{7}$ However, a concern is that dental practitioners may also feel pressurised into providing more restoratively invasive or destructive treatments, such as composite or porcelain veneers. This enters a child into the continuous restorative cycle, and guarantees that they will require maintenance, replacement and review of these restorations frequently. ${ }^{8} \mathrm{We}$ would hope that no dentist would place any indirect restorations on these immature teeth, but without the option of dental whitening some may feel it would be clinically justified.

\section{Conclusion}

With appropriate prescription, monitoring and review there can be no doubt that this treatment modality is incredibly safe and effective. As a specialism we are hugely concerned and disheartened that this excellent treatment option is no longer a possibility for children in the United Kingdom.

\section{Acknowledgements}

The authors would like to acknowledge the dental practitioners of Paediatric Dental Department of Charles Clifford Dental Hospital in Sheffield and the patients who have allowed publication of these cases.

\section{References}

1. Official Journal of the European Union. Council Directive 2011/84/EU. Available online at https:// eur-lex.europa.eu/LexUriServ/LexUriServ. do?uri=OJ:L:2011:283:0036:0038:en:PDF (accessed 5 September 2019).

2. General Dental Council. Tooth whitening and illegal practice. Available online at https://www.gdc-uk. org/information-standards-guidance/information-ondental-treatment/tooth-whitening-and-illegal-practice (accessed 5 September 2019).

3. Yee R, Wong V. Brexit: Implications for tooth whitening. Br Dent J 2016; 221: 211-212.

4. Hutchison C. Tooth whitening: a grey area. Br Dent J 2018; 225: 201

5. Rodd H, Noble F. Psychosocial impacts relating to dental injuries in childhood: the bigger picture. Dent $J$ (Basel) 2019; 7: 23.

6. Porritt J M, Rodd HD, Baker SR. Qualityoflife impacts following childhood dento-alveolar trauma. Dent Traumatol 2011; 27: 2-9.

7. Goldberg M, Grootveld M, Lynch E. Undesirable and adverse effects of tooth-whitening products: a review. Clin Oral Investig 2010; 14: 1-10.

8. Henry D B. The restorative cycle in dentistry. Todays FDA 2014; 26: 58-61; 63 